\title{
Clinical Events Start Relative to Reference Period
}

National Cancer Institute

\section{Source}

National Cancer Institute. Clinical Events Start Relative to Reference Period. NCI

Thesaurus. Code C87858.

An indication or description that the start of the clinical event is before, during or after a reference time interval. 